\title{
Modelagem Paramétrica de Muros: permeabilidade visual para urbanidade
}

\author{
Parametric modelling of walls: visual permeability to urbanity \\ - Rafaela Teixeira \\ Brasil \\ rafaelamt@outlook.com \\ - João V. Lopes \\ ISCTE-IUL, Portugal \\ Joint_ventura@hotmail.com
}

\begin{abstract}
Visually impermeable boundaries growth of residential multifamily buildings in Boa Viagem (Recife-BR) increases urban environment of buildings that ignore streets and pedestrians. Minimizing it, without disturbing the private use, this work consists in modelled walls defined by cobogós (typical hollow elements of the region), manipulated to guarantee some privacy and visual permeability at the same time. With Space Syntax tools and support, part of the neighborhood is analyzed both in its actual configuration, and after the post-supposed interventions. Analysis supported the design work decisions, making increase of visual range in public spaces possible, as a way of stimulate the urbanity.
\end{abstract}

Keywords: Visual Permeability, Urbanity, Parametric Modelling, Space Syntax, Cobogó

\section{Introduction}

The monotony and lack of visual permeability presented in the majority of the walls of the residential buildings boundaries in Boa Viagem (figure 01), leads us to search for a design solution, which alleviate its presence increasingly crescent in the city and the current hostile character related to these walls. The fact is that the big visually impermeable residential building boundaries increases the "blind points" in public spaces - it nourishes the feeling of insecurity in the city - and the number of visually disconnect regions that are geographically close to each other.

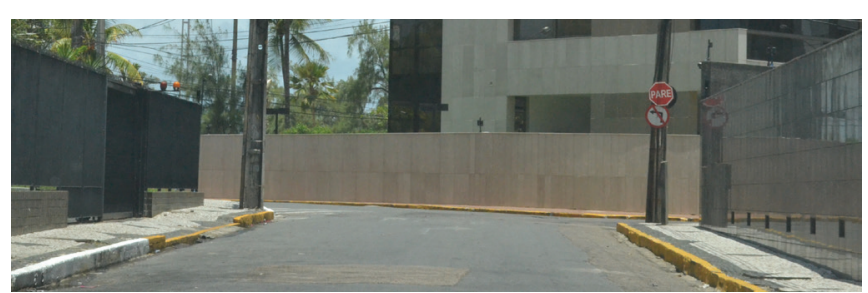

Figure 1: Residential buildings boundaries in Boa Viagem, Recife, Brasil. Foto by: Rafaela Teixeira (2013).

Using Space Syntax Theory (Hillier \& Hanson, 1980) and Isovists Theory (Benedikt, 1979), this work aims to analyze the consequence of setting the boundaries of residential buildings for urban space in its current configuration, and after apply the modelled walls of this work. Studies based on previously realized projects supported by Space Syntax theory, as well as parametric modelling, were necessary as a base knowledge to realize this work that consists on get together both areas of study (space syntax and parametricism), one to support the design decisions of the other.

The application of modeled cobogós walls (typical masonry hollow elements of the region) in the studied boundaries permits the manipulation of its visual permeability directly through specific parts of the private spaces, ensuring the privacy of others. The cobogó has increased its presence in some contemporary works with renewed shapes, colors and materials, for example the project Casa Cobogó, by Studio MK27, where we can see the potential of formal manipulation. Also the Assembly One Pavilion, created by first-year students from Yale School of Architecture, gives evidence of this visual direction manipulation. However, here the proposal is to manipulate its form-space according with parametric modeling and space syntax analyses, because of the many necessary variations in this kind of design process.

The main goal of this project is to promote the animation of urban space without disturbing the use of private space, using a local known architectonic element, and encouraging other boundary solutions for residential buildings. In addiction, it aims to analyze which could change, in terms of social life, different variations in the definition of those boundaries, enabling or restricting the visual permeability 
through the walls of residential buildings.

The Space Syntax methodology is based on the identification of spatial entities like convex spaces, axial lines and isovists, which can explain space configuration and its relationship with human behavior. These elements varies with the walls that define the space. So if we minimize the number of impermeable wall situations, we either change the area of visible convex spaces - it's important to clarify that here the worked space in the analyses are the visible, not the accessible ones. In this way, if we change the visible convex spaces, we change the connections between neighboring areas, so its syntax reality. Increasing the different public spaces connections and minimizing the quantity of its blind points stimulates the city life and mitigates the hostile character of the area.
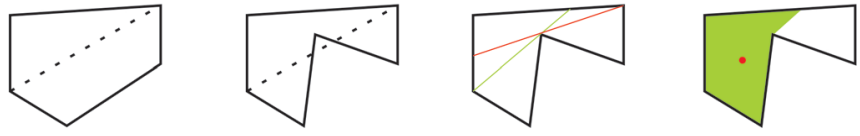

Figure 2: Illustration of a convex space, a no convex space, axial lines in a convex spaces system and an isovists map, respectively.

The modeled hollow walls produced here to apply in boundaries of buildings in a specific chosen area in Boa Viagem, has variations on its rotations, directing the gaze of passers in the urban space. These gazes are possible to be previously viewed through the generation of the set of axial lines, from the supposed rote or layout point of the observer that consists in the area of possible isovists. In this way, this cobogó walls that permits views through it - needs a defined wall project, in case of construction, and qualified hand worker.

\section{Methods}

The current situation of the residential buildings boundaries with two or more facades facing sidewalks in the neighborhood of Boa Viagem in Recife was observed through space syntax analysis. In the same way, post possible intervention on the walls was also analysed - Those practical works realized here were about the Walt Disney Square, where there is an urgent situation of no use. Finally, this paper presents a parametric modeling system of hollow walls with the implementation of targeted cobogós according to the direction of possibilities of views through it, in a way of ensure relative privacy to the private space of the buildings.

\section{Study objects}

In a previous work, it was made by Rafaela Teixeira (2013) an identification of the elements that characterize the boundaries of residential buildings in the neighborhood of Boa Viagem in Recife - just boundaries of residential buildings that have two or more facades adjacent to sidewalks around some of the busiest roads in the study area was observed. It was possible to see that the visually impermeable wall is the main element of its conformation; it predominantly features the boundary between many residential buildings raised and adjacent sidewalks. So, since the study area is mostly residential, this situation reflect to a monotony public area, an increase of the hostile character of it, the presence of many blind points in the neighborhood and many close places visually disconnected and nourishes the feeling of insecurity in the city. Among the main reasons expressed, about the use of impermeable walls, the issue of security and privacy is the main, and it throws the challenge of increasing the visual permeability without bother the characteristic private use of residential buildings.

After this surveying of the boundaries of the buildings, it was also possible to detect the cobogó with potential for future projects, as existing constructive elements in the reality of the studied buildings. The Cobogó is a hollow element, at first made in cement, which was designed by two merchants and one engineer settled in Recife, Pernambuco: Amadeu de Oliveira Coimbra, Ernest August Boeckmann and Antonio de Gois, respectively. This element usually makes up walls and, because it is leaked, allows the passage, from one side to another, of ventilation, light and view. The cobogó has increased its presence in some contemporary works with renewed shapes, colors and materials, and it is possible to manipulate in a way of direct the looks through it, due to its "hollow brick" geometry.

\section{Researches}

This work is developed with the help of the theory and methodology of Space Syntax, conceived by Hillier \& Hanson and colleagues around 70's, that consists on the theory of social logic of space, and its main goal: the understanding of how the space configuration can interfere with social reality. Currently, for the parsing of an open spaces arrangement, it is necessary to break it down into a system of spatial units with one and two dimensions (axial and convex) from which it makes possible the various types of measurement of the relations of its spatial components. The basic syntactic elements for analysis are the convex space (space where no line, formed between any two points on its perimeter, crosses it) and the axial line (higher straight lines able to cover the entire system of open spaces) that, next to isovistas (all visible points from a defined point in space) - key elements for the analyzes in this work form the group of the three basic concepts (figure 2). From this, it is possible to obtain all the syntactic measures, and the development of graphics, which give scientific foundation, on probabilities, for projectual interventions.

It has also studied and analyzed theoretical and practical works already performed, according to the studies in this thesis. Those standed out, made based on space syntax, are the revitalization project of Trafalgar Square in London held by Foster and Partners architectural firm, and the dissertation of Robson Canuto da Silva, in Urban Development master, entitled Urbanismo Paramétrico: parametrizando urbanidade, held at the Federal University of Pernambuco, and finalized in 2010. Respectively, one used the Space Syntax for the project with 
the analysis of pedestrian flows and, from it, the development of a pedestrian movement model, enabling the identification of problems of the director plan in the area, and other suggested that the configuration parameters of space, analyzed in space syntax, could also be aggregated in the development of parametric urban design process for an urban area with more vitality.

Beyond the ones based on Space Syntax, it was also identified practical works on visual permeability possibilities. For example, the Assembly One Pavilion, project created by first-year students from Yale School of Architecture, where they used dynamism, visual transparency and visual density toguide their project process, with the use of digital technology. With this pavilion it is obvious the digital manipulation to direct where it is possible or not to view through it. Another project is the Casa Cobogó by Studio MK27, where there were walls made by Cobogós that make us think about the potencial of formal manipulation of cobogós through the digital technologies, now it can be digitally designed and produced, so there are a lot of new formal possibilities as well as ways of manipulation of the views through it.

From the study of works like these, some performed based on Space Syntax and others taking advantage of the potential of digital production, the purpose of this paper is to add an analysis based on space syntax - in this case, analysis based on isovists - with the advantages of parametric modeling. The cobogós were identified as typical elements of the area (Recife, Brasil) with handling potential for this work, as already explained here, because they are hollow and there are manipulation possibilities of possible viewing directions through them.

\section{Analyses processes}

The first experimentations on Space Sintax analyses had most importance for justify the social necessity of the minimization of the big walls and blind facades, in the boundaries of multifamiliar residential buildings in the study area. By way of analysis, the Walt Disney Square was highlighted in the studied neighborhood. This was decided because it is a children's playground located between residential buildings, very close to the seaside (quite busy area) but that has very little use of people in it - a fact that coincided with the analysis of integration of the urban grid of the neighborhood as a whole (figure 3 and 4). To investigate the possibility that it is a spatial configuration issue, the map of Boa Viagem was introduced into Depthmap, and it was set barriers in accordance with the views of pedestrians in urban areas, to generate graphics that would show us the situation of its configuration with its surroundings.

By generating the axial graph, it was possible to identify the Walt Disney Square as disconnected with the other areas of the city that are part of its immediate surroundings, so this may be contributing to their abandonment by the pedestrians. It was chosen in this first phase to compare the extreme cases of permeability of its buildings boundaries. At first, it was analyzed as the boundaries of residential buildings were completely walled without any visual permeability. The opposite extreme case analyzed was assumed as if all distances, of the boundaries to the buildings, required by law for this type of building, could be $100 \%$ utilized in terms of visual permeability by people present in the public space. With the generation of a visibility graph analyses (VGA), on these two alleged situation, clearly was realized that this intervention ends up generating greater connectivity between the studied square and other areas of the neighborhood. This is better seen through the mathematical information obtained through the generation of these charts (table 1). In addition, the possible social consequences for the city could be see, as of changes the settings of the limits of many multifamily buildings in addition to factors such as increased safety and comfort of the path through public spaces, due to expansion of the visual field and landscape animation.

\begin{tabular}{|c|c|c|}
\hline $\begin{array}{c}\text { Visibility Graph } \\
\text { Data (average) }\end{array}$ & $\begin{array}{c}\text { No permeability } \\
\text { situation-01 }\end{array}$ & $\begin{array}{c}\text { Total } \\
\text { permeability-02 }\end{array}$ \\
\hline Connectivity & 2476.55 & 3285.79 \\
\hline Integration $[\mathrm{HH}]$ & 10.8416 & 13.0398 \\
\hline
\end{tabular}

Table 1: VGA data about connectivity and integration values, in an area of $90 \mathrm{~m}$ radious from the center of the square.
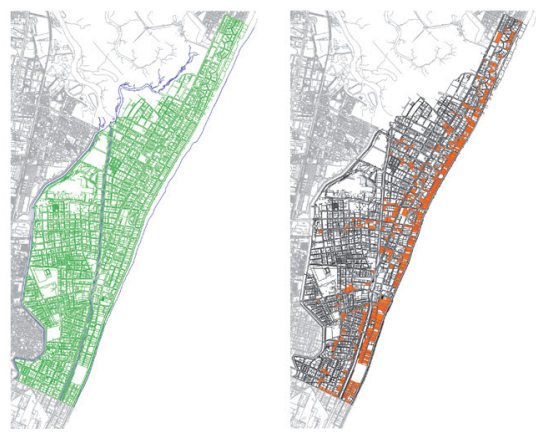

Figure 3: Boa Viagem map and the identification of all residential buildings in it with two or more facades adjacent to sidewalks, in its main streets.

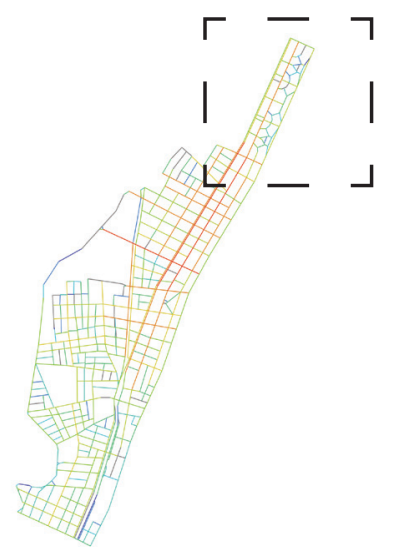

Figure 4: Integration map with axial lines in the Boa Viagem grid. Also, it's perceived the no integrated Walt Disney Square. 


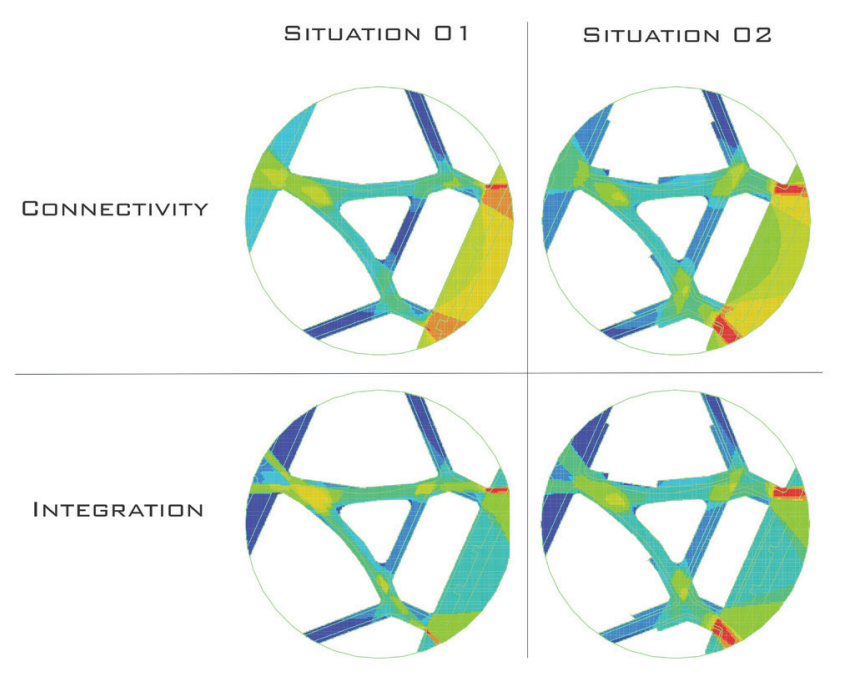

Figure 5: VGA maps generated on situation 01 (no permeability) and situation 02 (total permeability) around Walt Disney Square with Connectivity and Integration $[\mathrm{HH}]$ data.

\section{Parametric modelling}

As already explained, besides the need for greater visual permeability in the boundaries in order to improve the city's urbanity situation, the residential buildings requires a high degree of privacy, and for this reason, the permeability cannot be fully guaranteed. Based on this, the option to model these possible boundaries through the uses of cobogós got stronger, because of the possibility of directions of possible views through them to specific locations in the space of intervention. Besides the fact these are hollow elements, the choice of Cobogó also get strength due to the fact that it's a typical masonry of the region. For this work, seeking greater possibility of real development, it was decided to study rotated cobogós application, according to the floor plan, in order to gradually drive Pedestrians look, at the corners of the residential buildings (figure 6). In this way, through the Grasshopper, plug-in for Rhinoceros software, it was possible to design a wall of modulation to be set in the boundaries corners of these buildings surrounding the Walt Disney Square parametrically. The parametricism becomes important to allow less time spent in the definition of the architectural design of rotated cobogós wall as well as the definition of gradual steering of rotation, also to analyze possible isovists in real time during design phase (figure 7).
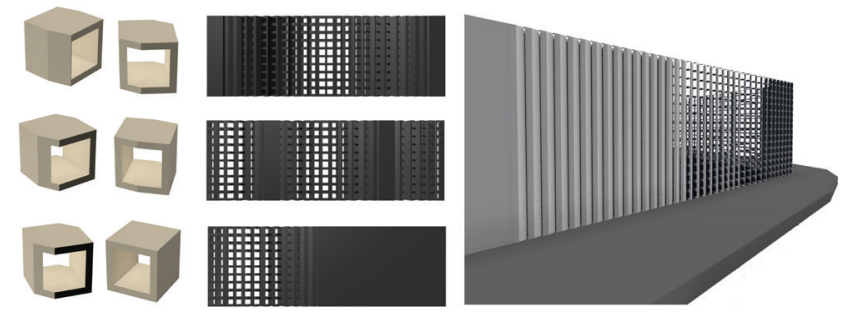

Figure 6: Modeled images of the six different blocks of cobogós generated by rotations, also three possible variations of walls and an example of application in a corner boundary.

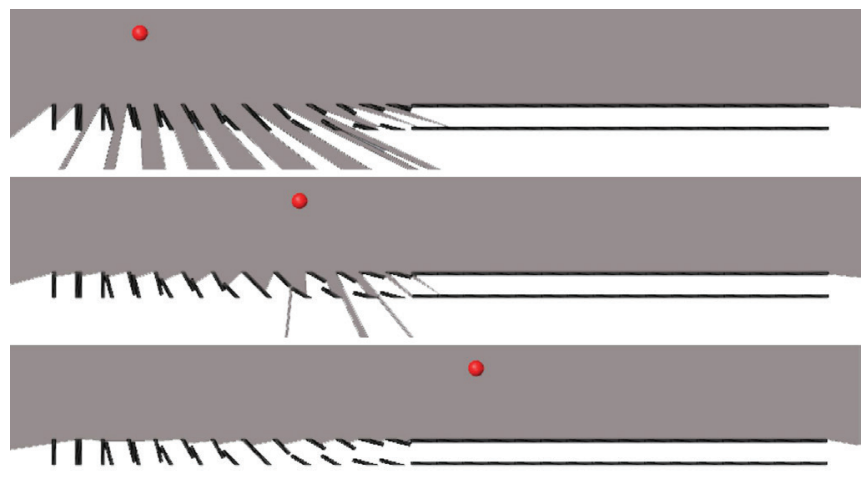

Figure 7: Real time analyses of isovistas through the modelled cobogó's wall in a route of a supposed pedestrian.

\section{Results}

The product of this work consists in two steps in the design stage: one is the analytical and other the modelling. The digital work allowed this simultaneous association and in a parametric workflow. It was possible by the manipulation of the various key parameters in the case of this work: height of the wall, rotation of cobogós located in boundaries of residential buildings, route of possible pedestrians, etc. It is possible, through the parametric software, the $3 \mathrm{D}$ visualization of digital manipulation performed in real time, the generation of a 2D plan equivalent to this, as well as the generation of isovists according to the location of the pedestrian or the definition of its route. With this, it is also possible to generate the post-intervention results, by sending the floorplan of its results to the Depthmap (figure 8) - Space Syntax Software - to generate the visibility graph analyses (table 2) and, after that, compare again with the extreme reality of boundaries completely walled around the Walt Disney Square.

\begin{tabular}{|c|c|c|}
\hline $\begin{array}{c}\text { Visibility Graph } \\
\text { data (average) }\end{array}$ & $\begin{array}{c}\text { No permeability } \\
\text { situation-01 }\end{array}$ & $\begin{array}{c}\text { Permeability } \\
\text { of intervention } \\
\text { situation-03 }\end{array}$ \\
\hline Connectivity & 2476.55 & 2670.15 \\
\hline Integration [HH] & 10.8416 & 11.8234 \\
\hline
\end{tabular}

Table 2: VGA data about connectivity and integration values, in an area of $90 \mathrm{~m}$ radious from the center of the square.

Through the analyzes that were conducted, the possibilities for different and numerous cobogós layout, and compounded with the need to define together the rotation of cobogós in one facade with its adjacent one, it was concluded that the real reality is quite far from ideal reality - considered here the full use of the necessary distance, between the boundaries and the buildings, according to the law - in terms of syntactic results. However, based on the visibility data displayed in the comparison table above, there was 
a substantial improvement in the degree of connectivity and integration through permeability between the areas of the space of the system studied. Lastly, it's concluded the importance of the space syntax study and methodology, as well as parametric systems based works, together, as an alternative of make the architectonic production more close to its consequences about the configuration of urban spaces and its probable consequent urbanity.

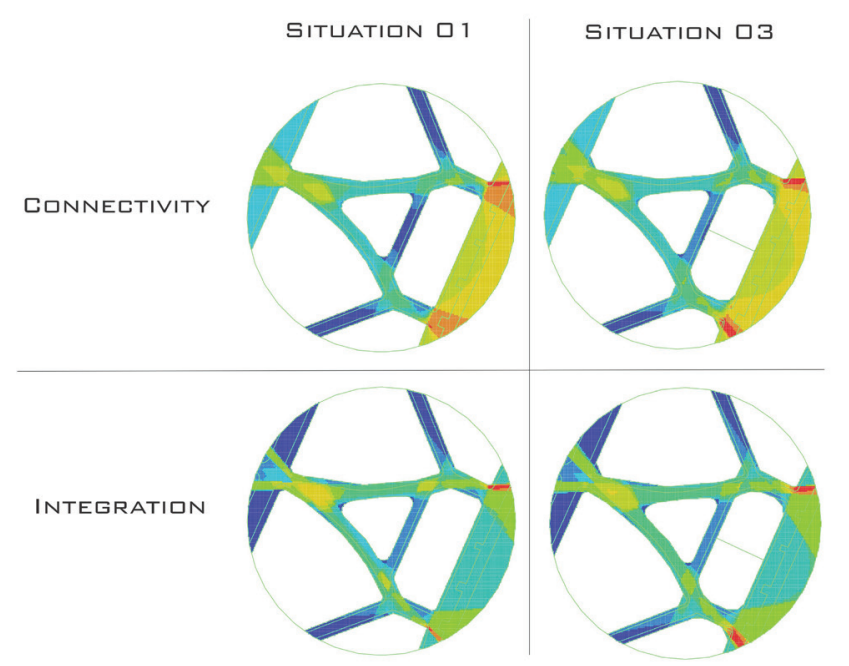

Figure 8: VGA maps generated on situation 01 (no permeability) and situation 03 (post cobogós intervention in the buildings boundaries corners) around Walt Disney Square with Connectivity and Integration $[\mathrm{HH}]$ data.

\section{Discussion}

The theory and methodology regarding the Space Syntax is an indispensable tool for analysis of social effects from the configurational definitions of space. Through it is possible to correlate the configuration of existing space or designed with likely forms of use (natural movement, accessibility, distribution of land use, transport movement, among others). Thus, it can be concluded that the space syntax contributes to the possibility of syntax analysis with highest possible accuracy of the configuration of architectural plans which make up the city, in view of the possible measured as the inhibition or stimulation of social use of space city in question, with the ultimate goal of stimulating interventions that seek encouragement and improvement of urban life in cities.

The methodology based on the theory of space syntax, in isolation, is not able to allow development of projects, since it does not produce results, it allows actually the analyze of the layout of open spaces systems, allowing a view the conformational spaces system quickly and based on mathematical calculations. For these reasons, the syntactic methodology needs to be linked to a working method that allows their use as assistant in project definition. Therefore, it is interesting to work with a project design method that allows for continuous analysis of the possible social and spatial consequences, based on space syntax, from the design stage to the project definition.

Lastly, from this work to future possible works based on this one, we can discuss about two topics of development ways. One of these, is the conclusion that the syntactic elements used in the analysis of projects may also contribute to the designs of the configuration of buildings' boundaries, if analyze it in their relationship with the city, in order to promote urbanity. The other one is about the selection of one of the many possibilities of digital manipulation on a wall setting defined by cobogós, so that introduces possible future works that get together the countless amount of formal manipulation possibilities of these elements with the direction of visions through them, tied to a syntactic-spatial analysis.

\section{Acknowledgments}

Thanks to all the teachers and colleagues that incentivize and share theoretical bases to reflections about the urban spaces. Specially, to the architect Diego Pessoa, for stimulate this production and for being always available to help in the concretization of this work. Besides those, to all professors and students of the post-graduation Curso de Estudos Avançados em Arquitetura Digital (CEAAD), taught in Lisbon, in the ISCTE-IUL (Instituto Universitário de Lisboa) environment, who collaborated with important knowledge exchanges to enrich and strengthen the arguments and proposals here.

Co-author João V. Lopes is supported by FCT SFRH/ BD/95148/2013 research grant.

\section{References}

Benedikt, M. L.. (1979) "To take hold of space: isovistas and isovist fields" Environment and Planning B 6(1) 47-65.

Borba, C., Rodrigues, J., Vieira, A. (2012). Cobogó de Pernambuco. Recife, Pernambuco: Josivan Rodrigues.

Foster \& Partners. [Projects]. Retrieved from <http://www. fosterandpartners.com/>.

Hillier, B., Hanson, J. (1984). The Social Logic of Space. Cambridge: Cambridge University Press.

Hillier, B., Leaman, A, Atansall, P, Bedford, M. (1976). Space Syntax. Environment' and Planning B: Planning and Design, 3,147-185.

Hillier, B. (1989). The architecture of the urban object. Ekistics 56.

Hillier, B. (1996). Space is the machine. Cambridge: Cambridge University Press.

Holanda, A. de. (1976) Roteiro para construer no Nordeste: Arquitetura como lugar ameno nos trópicos ensolarados. Recife, Pernambuco: Ed. Universitária da UFPE.

Jacobs, J. (2011) Morte e vida de grandes cidades. $3^{\text {a }}$ Ed. São Paulo: Ed. WMF Martins Fontes.

Karqvist, Bjorn. (1992). "A Space Syntax Glossary", Nordic Journal of Architectural Research, 1993:2, 11-12.

Koolhaas, R. (2014). Balcony: series of 15 books accompanying 
the exhibition elements of architecture at the venice architectire biennale. Italia: Marsilio.

Lei $N^{\circ}$ 16.292/97 - Código de Edificações e Instalações na Cidade do Recife. Disponível em: http://www.legiscidade. recife.pe.gov.br/lei/16292/ Acesso em: março de 2015.

Leitão, L. (2009). Quando o ambiente é hotel: uma leitura urbanística da violência à luz de Sobrados e Mucambos e outros ensaios gilbertianos. Recife, Pernambuco: Ed. Universitária da UFPE.

Pallasmaa, J. (2011). Os olhos da pele: A arquitetura e os sentidos. Porto Alegre: Ed. Bookman.
Rosenfield, K. (2012, Jul 01). "Assembly One Pavilion / Yale School of Architecture Students". ArchDaily. Retrieved from http://www.archdaily.com/250097/assembly-one-pavilionyale-school-of-architecture-students/

Silva, R. C. da. (2010). Urbanismo paramétrico: parametrizando urbanidade. Recife, Pernambuco: Ed. Universitária da UFPE. Space Syntax, Limited, UK. Retrieved from htttp://www. spacesyntax.com

Space Syntax Network. Retrieved from http://www. spacesyntax.net 